\title{
Systems thinking in 21st century: a call to health promoters
}

\author{
Sudesh Raj Sharma ${ }^{1^{*}}$, Anna Matheson ${ }^{1}$ \\ ${ }^{1}$ College of Health, Massey University, Wellington
}

\section{Received:}

16 February 2016

Revised:

25 May 2016

\section{Accepted:}

28 June 2016

\section{${ }^{\star}$ Correspondence: yoursudesh@gmail.com College of Health, Massey University, Wellington.}

Health Promotion often deals with complex issues that are multi-factorial and multi-level such as malnutrition, maternal mortality and non-communicable diseases. In theory, health promotion boasts of using ecological and holistic approaches to improving public health but in practice, health promotion is dominated by the medical model (linear causal view) $(1,2)$ despite repeated calls for a more comprehensive approach $(3,4)$. Approaches to health promotion based on the medical model have merits but their sustainability and benefits to human development have time and again been questioned $(2,5,6)$. For example, there have been significant achievements in the reduction of mortality for mothers, newborns and children in developing countries due to simple technological interventions $(7,8)$. However, at the same time, the problem of noncommunicable disease is growing rapidly (9). Further, underlying root causes of public health problems such as poverty, access to quality health services and the empowerment of women remain unresolved. The lack of progress in addressing the root cause of complex health problems indicates that our existing approaches are failing and needs an alternative way of thinking. Systems science based thinking could provide appropriate scientific foundation for health promotion discipline to address complex health problems and its root causes $(10,11)$. In this short essay, we will explain why health promotion, as a discipline needs to bring system science perspective to deal with the multitude of health problems that developed and developing countries are facing alike.

First, let us understand what a complex system is and how systems thinking can be applied to it. A system is a congregation of the elements or structure which are interlinked with each other exhibiting an emergent behaviour over time (12). So, basically a system has three main aspects: structure, behaviour and interconnections. A complex system is composed of multiple elements operating at multiple levels with multiple interconnections and multiple emergent behaviours (13). Some key attributes of complex system include that they are self-organizing, dynamic, non-linear, governed by feedback, history-dependent and resistant to change (14). Social systems can be considered a complex system of human interrelationship with multiple structures interacting and influencing each other resulting in certain way of behaviour $(13,15-17)$.

A systems view sees public health problems like non-communicable diseases, maternal and newborn mortality and malnutrition as an undesirable behaviour being generated from the interaction and functioning of social system structures $(10,16)$. System thinking can be utilized both to understand the complex public health problems like NCD and identify strategies to mitigate the undesirable behaviour by actions on interconnections and structure. In the discipline of health promotion, the chorus is getting louder for utilising "systems science" due to the alignment of the epistemological and methodological stances of health promotion (11). Epistemologically, system science recognises the dynamic, non-linear and reflexive behaviour of social systems and takes a relativistic, subjective and critical viewpoint towards establishing a truth. This is consistent with health promotion discipline which emphasize on participatory and empowering approach (thus value-laden) to health improvement in a complex social setting. Methodologically, system science emphasizes mixed-method approaches to better understand the complexity of an issue. This also sits comfortably with the transdisciplinary nature of health promotion discipline. Common systems science methods applied in the public health field include agent based modelling, network analysis and system dynamics (18). They utilize the mixed-method approach for the synthesis and analysis of causal factors. One prominent systems thinker, in particular, has emphasized methodological pluralism in order to understand the complex dynamics of public health problems within a context (19). System thinkers should not be bounded by limited methods but continually strive to utilize multi-disciplinary approaches to understand complex reality. For example, system dynamics method (primarily a quantitative approach) is often combined with qualitative research strategies for improving research design and scientific reasoning of complex issues (20-22).

Systems thinking is proving to be a promising approach to understanding and dealing with complex public health problems where interactions are key $(23,24)$. Just like the popular story of "Five blind men and the perception of the elephant's body" where there is need for a comprehensive approach like systems thinking that could connect the incorrect mental models of each of the blind men and assist in developing a holistic shape of the elephant that reflects the reality. World Health Organization has developed the 
"Social Determinants of Health" framework which elucidates the complexities involved in addressing health equity (25). Similarly, the popular "Ecological model" of health promotion also describes the complexities of health promotion actions (26). These frameworks and others present a broad range of factors associated with complex public health problems. However, there is suggestion that these frameworks may be improved upon and allow greater contextualization through identifying gaps in practice, and enable better design of effective interventions if a complex systems approach is applied (27). Systems methods and tools are better suited for illuminating the dynamic structure and emergent behaviour leading to complex health problems.

In Nepal as well as globally, health promotion (and public health) have been late in adopting the approaches and reaping the benefits of systems science (10). Itis high time that the health promoters embraced this innovative set of approaches in our research and practice which is well integrated within the management and other social science field (28-31). Some key complex health challenges that could be on this agenda include non-communicable diseases and risk factors prevention, maternal and child health promotion, health system strengthening and health policy analysis. Particularly in non-communicable disease prevention, systems thinking could be an effective approach for health promoters to tackle the actions of the corporate giants (mainly tobacco, alcohol and fastfood industries) who are already using systems approach for their gains and health promotion's loss $(32,33)$.

\section{References}

1. Cueto M. The ORIGINS of Primary Health Care and SELECTIVE Primary Health Care. American journal of public health. 2004;94(11):1864-1874.

2. McCoy D, Kembhavi G, Patel J, Luintel A. The Bill \& Melinda Gates Foundation's grant-making programme for global health. The Lancet. 2009;373(9675):16451653.

3. World Health Organization. Milestones in health promotion: Statements from global conferences. Geneva: World Health Organization; 2009.

4. UNICEF, World Health Organization. Primary health care: report of the International Conference on Primary Health Care, Alma-Ata, USSR, 6-12 September 1978. 1978 .

5. Beaglehole R, Bonita R. Public health at the crossroads: achievements and prospects. Cambridge University Press; 2004.

6. Werner D, Sanders D. The demise of primary health care and the rise of the child survival revolution In: The politics of primary health care and child survival. Palo Alto (CA). Health Wrights. 1997:23-30.

7. Darmstadt GL, Bhutta ZA, Cousens S, Adam T, Walker N, de Bernis L. Evidence-based, cost-effective interventions: how many newborn babies can we save? Lancet. $2005 ; 365$.

8. UNICEF. Committing to Child Survival: a Promise Renewed-Progress Report. United Nations Children's Fund (UNICEF); 2014.

9. World Health Organization. Global Status Report on noncommunicable diseases 2014. World Health Organization;2014.

10. Green LW. Public Health Asks of Systems Science: To Advance Our Evidence-Based Practice, Can You Help Us Get More Practice-Based Evidence? American journal of public health. 2006;96(3):406-409.

11. Tremblay M-C, Richard L. Complexity: a potential paradigm for a health promotion discipline. Health promotion international. 2014;29(2):378-388.

12. Meadows DH. Thinking in systems: A primer. White River Junction, VT: Chelsea Green; 2008.

13. Roux AVD. Integrating social and biologic factors in health research: a systems view. Annals of epidemiology. 2007;17(7):569-574.

14. De Savigny D, Adam T. Systems thinking for health systems strengthening. World Health Organization; 2009.

15. Sterman JD. Business dynamics: Systems thinking and modeling for a complex world. Boston: Irwin/McGraw-Hill; 2000.

16. Luke DA, Stamatakis KA. Systems science methods in public health: Dynamics, networks, and agents. Annual review of public health. $2012 ; 33: 357$ - 376.

17. Sawyer RK. Social emergence: Societies as complex systems. Cambridge University Press; 2005.

18. Luke DA, Stamatakis KA. Systems science methods in public health: dynamics, networks, and agents. Annual review of public health. $2012 ; 33: 357$.

19. Midgley G. Systemic Intervention for Public Health. American journal of public health. 2006;96(3):466-472.

20. Rwashana AS, Williams DW, Neema S. System dynamics approach to immunization healthcare issues in developing countries: a case study of Uganda. Health informatics journal. 2009;15(2):95-107.

21. Vandenbroeck P, Goossens J, Clemens M. Foresight, Tackling Obesities: Future Choices-Building the Obesity System Map. London: Government Office for Science. 2007.

22. Merrill JA, Deegan M, Wilson RV, Kaushal R, Fredericks K. A system dynamics evaluation model: implementation of health information exchange for public health reporting. Journal of the American Medical Informatics Association. 2013;20(e1):e131-e138.

23. Finegood DT, Cawley J. The complex systems science of obesity. The Oxford handbook of the social science of obesity. New York: Oxford University Press; 2011:208-236.

24. Homer JB, Hirsch GB. System dynamics modeling for public health: Background and opportunities. American journal of public health. $2006 ; 96: 452$ - 458.

25. Solar O, Irwin A. A conceptual framework for action on the social determinants of health. World Health Organization;2007.

26. Sallis JF, Owen N, Fisher EB. Ecological models of health behavior. Health behavior and health education: Theory, research, and practice. 2008 ; 4:465-486.

27. Matheson A. Reducing social inequalities in obesity: complexity and power relationships. Journal of Public Health. 2016.

28. Mabry PL, Milstein B, Abraido-Lanza AF, Livingood WC, Allegrante JP. Opening a window on systems science research in health promotion and public health. Health Education \& Behavior. 2013;40(1 suppl):5S-8S.

29. Midgley G. Systemic intervention: philosophy, methodology and practice. New York: Kluwer Academic/Plenum Publishers; 2000.

30. Sterman JD. Business dynamics: systems thinking and modeling for a complex world. Vol 19: Irwin/McGraw-Hill Boston; 2000.

31. Meadows D, Randers J, Meadows D. Limits to growth: the 30-year update. Chelsea Green Publishing; 2004. 